\title{
Down's Syndrome Child With Subglottic Stenosis: A Case Report
}

\author{
A Kahairi, R Ahmad, M Lukman
}

\begin{abstract}
Citation
A Kahairi, R Ahmad, M Lukman. Down's Syndrome Child With Subglottic Stenosis: A Case Report. The Internet Journal of Otorhinolaryngology. 2005 Volume 4 Number 2.
\end{abstract}

DOI: $\underline{10.5580 / 1063}$

\section{Abstract}

An asymptomatic subglottic stenosis in Down's syndrome can be missed. This problem will be manifested after the child had certain general anaesthesia procedure. We describe a Down's syndrome child with subglottic stenosis (Cotton grade III) whom was diagnosed after underwent cardiac surgery for congenital heart disease which was successfully treated by endolaryngeal microscopic laser treatment.

\section{CASE HISTORY}

A 3-year-old girl was diagnosed as Down's syndrome with ventricular septal defect since birth. However she has defaulted the follow-up at the pediatric clinic and at the age of 5 month she developed pulmonary hypertension with cardiac failure where she was admitted to the ward. She was then referred to National Heart Institute in which the congenital heart disease was corrected on January 2003. Post operatively; she was ventilated in Intensive Care Unit for 12 days. Immediately after extubation she was noted to develop noisy breathing but this was not associated with cyanosis, difficulty in breathing or feeding. She was referred to Ear Nose and Throat (ENT) clinic on June 2003. On further enquiry her parent noted that prior to the cardiac surgery their child do have a problem of noisy breathing especially when she developed respiratory tract infection. Examination under anesthesia, which was done on July 2003, showed subglottic stenosis Cotton Grade III (90\% stenosis) (figure 1) that is membranous type and is about $0.6 \mathrm{~cm}$ below the vocal cord. Laser excision of the subglottic stenosis was done on March 2004 (figure 2). Intraoperatively it was noted that the length of stenosis is less than $10 \mathrm{~mm}$. Day one post operatively, mother claimed that the child had less stridor and she was able to utter few words. Three month later during follow-up at ENT clinic, there was no stridor noted.

\section{Figure 1}

Figure 1: membranous stenosis below the vocal cord with little opening at the posterior aspect of the glottic inlet (black arrow)

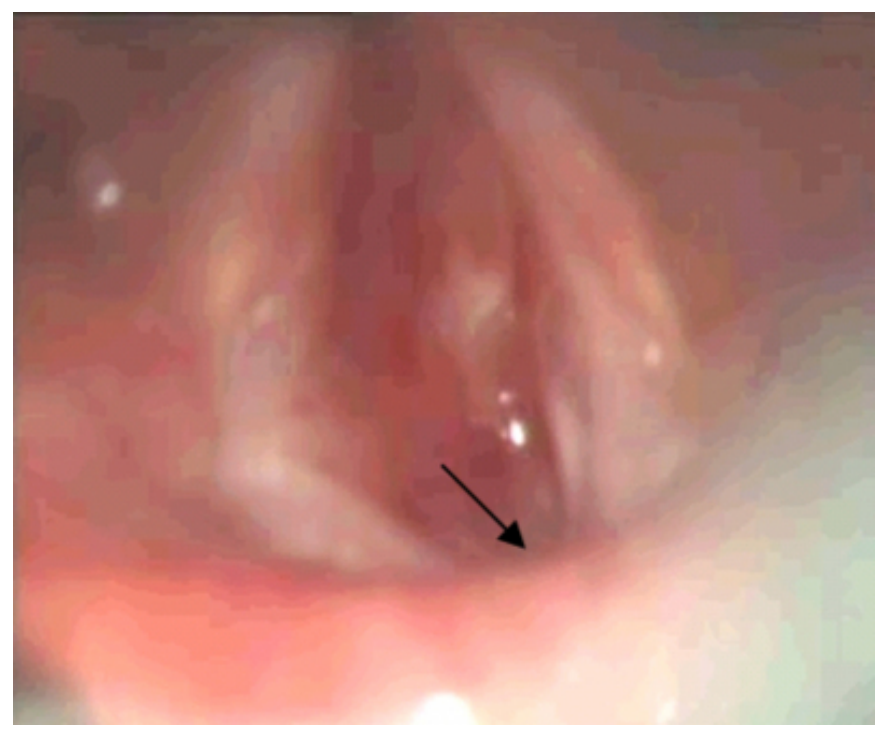




\section{Figure 2}

Figure 2: Post laser ablation of the stenosis

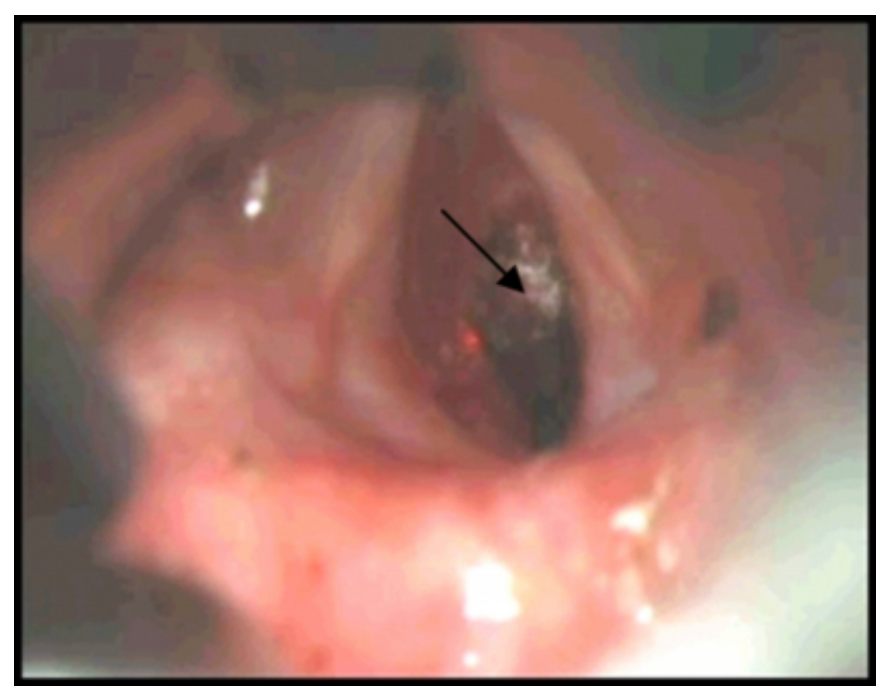

\section{DISCUSSION}

Incidence of paediatric subglottic stenosis has shown a reduction over the past 30 years and this might be due to improve techniques of handling paediatric who require ventilatory support. The current incidence was no more than $0.63 \% ._{1}$ Paediatric subglottic stenosis can be divided into congenital or acquired. Majority of the cases are acquired subglottic stenosis and most commonly resulting from endotracheal intubation and the associated inflammatorytype response.

Multiple congenital anomalies are closely linked to Down syndrome (trisomy 21) and a reported incidence of subglottic stenosis in Down syndrome is $6 \% ._{2}$ This child might have had an asymptomatic subglottic stenosis at birth and during intubation for the cardiac surgery; inappropriate size of endotracheal tube might be used for this child that may be too tight in the subglottic area. By aggravating a previously asymptomatic subglottic stenosis and long-term endotracheal intubation in this patient may be more likely to contribute to a clinically significant subglottic stenosis. Other factors, which may contribute to the exacerbation of this stenosis, are the presence of upper respiratory tract infection and laryngopharyngeal reflux particularly in a ventilated child.

Management of subglottic stenosis in children is a real challenge and it's depending upon severity of the stenosis using Myer - Cotton's grading system for subglottic stenosis. ${ }_{3}$ In the majority of cases with a Grade I stenosis, conservative management may be all that is required but in Grade II and above, surgical intervention is the preferable treatment. Techniques for repairing the airway consist of two basic modalities: endolaryngeal and external approaches. In weighing the advantages of endolaryngeal versus external or open procedures, the surgeon's personal expertise and the lesion severity should serve as a guide. It is important to assess the stenosis under general anesthesia prior to the definitive treatment where the site, the Cotton's grading of the stenosis, the length of the stenosis and finally the consistency of the stenosis either membranous, cartilaginous or mixed will be determined. Magnetic Resonance Imaging also helpful to assess the site and length of the stenosis especially if the child's general condition is not permissible for general anesthesia because of other congenital heart problem.

$\mathrm{CO}_{2}$ laser is the preferred modality in the management of early stenosis, grades II and III. This technique facilitates vaporization of scar tissue with precision and minimal damage to healthy tissues. Laser resection is a viable alternative to surgery and it has the advantages in reducing the timing of operation in patients with subglottic stenosis with very minimal bleeding. However this only applied to stenosis which length is less than $10 \mathrm{~mm}$, as the above case. For those with length more than $10 \mathrm{~mm}$, open-neck surgery by laryngoplasty or laryngotracheal resection and anastomosis is recommended. ${ }_{4}$ Several endolaryngeal laser procedures may be necessary to ablate the recurrence of stenosis. Successful endolaryngeal control of airway stenosis depends on several factors. These factors include the ease of endoscopic visualization (individual anatomic factors), the severity of the stenosis and the type of stenosis (firm vs. soft). This child needs a long-term follow-up to assess for any recurrence.

In conclusion proper selection of endotracheal tube in a Down syndrome patient is very important in which it might prevent development of subglottic stenosis. In selected cases, endolaryngeal laser treatment is not only reducing the operative time, hospital stay and total treatment cost but also able to provides good outcome.

\section{CORRESPONDENCE TO}

R. Ahmad MS(ORL-HNS) Dept. of Otolaryngology - Head $\&$ Neck Surgery, Faculty of Medicine, International Islamic University Malaysia, Jalan Hospital, 25100, Kuantan, Pahang, Malaysia. Tel: 609-5132797 Fax: 609-5133615 Email:rahmad@iiumedic.edu.my

\section{References}

1. Walner, David L, Loewen, Mark S, Kimura, Robert E. Neonatal Subglottic Stenosis - Incidence and Trends. 
Laryngoscope. 2001 Jan; 111(1): 48-51.

2. De Jong AL, Sulek M, Nihill M, Duncan NO, Friedman EM. Tenuous airway in children with trisomy 21 .

Laryngoscope. 1997 Mar; 107(3): 345-50.

3. Myer C.M., O'Connor D.M. \& Cotton R.T. (1994)

Proposed grading system for subglottic stenosis based on endotracheal tubes sizes. Ann. Otol. Rhinol. Laryngol. 103, 319-323

4. Giudice M, Piazza C, Foccoli P, Toninelli C, Cavaliere S, Peretti G. Idiopathic subglottic stenosis: management by endoscopic and open-neck surgery in a series of 30 patients. Eur Arch Otorhinolaryngol. 2003 May; 260(5): 235-8. Epub 2002 Nov 22. 


\section{Author Information}

\section{A. Kahairi, MBBS}

Department of Otolaryngology-Head \& neck Surgery, Faculty of Medicine, International Islamic University

\section{R. Ahmad, MS (ORL-HNS)}

Department of Otolaryngology-Head \& neck Surgery, Faculty of Medicine, International Islamic University

\section{Lukman, MM (Anaest)}

Department of Anaesthesiology \& Intensive Care, Faculty of Medicine, International Islamic University 